\title{
Cognitive abilities associated with the Silver-Russell syndrome
}

\author{
Kelly Y C Lai, David Skuse, Richard Stanhope, Peter Hindmarsh
}

\begin{abstract}
There is no consensus opinion on whether or not cognitive impairments are found in the Silver-Russell syndrome. An investigation of a substantial sample was undertaken, using standardised assessments, in 20 boys and five girls aged 6.0 years to 11.8 years. Mean (SD) birth weights were $-2.65(0.95)$ SD scores, corrected for gestation. At evaluation the children had a mean (SD) age of $8.8(1.8)$ years and a mean height of $-2.26(1.5)$ SD scores. Tests of cognitive abilities included assessments of general intelligence, reading and arithmetic attainments, and $a$ cognitive processing task. Most had some degree of developmental delay: mean (SD) full scale IQ was 86 (24); 32\% scored within the learning disability range (that is, IQ $<70$ ); $40 \%$ were reading at least 24 months below their chronological age. Current head circumference correlated highly with full scale IQ. Assessments of special educational needs had been completed on $36 \%$; $48 \%$ were receiving speech therapy. Approximately half of children with the Silver-Russell syndrome have significant impairment of their cognitive abilities.
\end{abstract}

(Arch Dis Child 1994; 71: 490-496)

In 1953, Silver described two children with body asymmetry, short stature, low birth weight, and abnormal sexual development. ${ }^{1} \mathrm{~A}$ year later, Russell reported five children who presented similarly with low birth weight and short stature, but only two had asymmetry. ${ }^{2}$ In addition, he noted the presence of characteristic craniofacial features and a shortened incurved fifth finger. In Silver's subsequent review of 29 similar cases reported in the literature, he found that these and other clinical features were often associated, but none was invariably present in any one case. ${ }^{3}$ Features that were more often reported included low birth weight $(93 \%)$, short stature $(93 \%)$, asymmetry $(78 \%)$, clinodactyly $(76 \%)$, and a craniofacial appearance similar to that described by Russell (50-62\%). ${ }^{2}$

The current view is that the Silver-Russell syndrome is a single entity, ${ }^{4}$ although no consistent criteria have been established for its diagnosis. Low birth weight and short stature are almost always present. Tanner et al have argued that it is probably a distinct condition from non-specific intrauterine growth retardation. ${ }^{5}$ It is characterised in particular by the presence of distinctive craniofacial features (small triangularly shaped face with relatively large forehead and small chin, downturned corner of the mouth sometimes known as a 'shark's mouth' appearance, and low set ears). Limb asymmetry, clinodactyly, and excessive sweating lend support to the diagnosis. There is no catch-up postnatal growth, so that affected children remain short and very lean through to middle childhood. 'Growth hormone deficiency may coexist. There are no sex or race differences in prevalence. The aetiology of the intrauterine growth impairment and the dysmorphic features is unknown.

While the physical development of affected children has been studied in detail, ${ }^{5-7}$ their cognitive development has received much less attention. Reports in the literature are inconsistent, and most are based upon clinical impressions. There do not appear to be any published reports of cognitive abilities based on formal measurements. Silver concluded in his review of 29 cases that 'significant mental retardation' occurred more often than would be expected by chance. ${ }^{3}$ In the series of Tanner et al, the intellectual abilities of 11 children were found to be within the normal range. ${ }^{5}$ In a sample of 15 children described by Saal et al, six of them were found to have either specific developmental delays (especially in the area of language) or frank mental retardation. ${ }^{6}$ Yet Patton has expressed the opinion that 'normal IQ is the rule'. ${ }^{4}$ Impairment of motor development has also been reported, and is usually attributed to an age inappropriate lack of muscle bulk and power.

We hypothesised that, similar to reported samples of low birthweight children, the cognitive abilities of children with Silver-Russell syndrome were likely to be impaired. Were this to be the case parents could be advised about the possibility of learning difficulties, and hence the potential need for extra educational provisions.

\section{Subjects and methods}

The Child Growth Foundation (a charitable organisation for families with children with growth problems) and the growth clinics of 
two university teaching hospitals were approached for the names of children who had been diagnosed as having the Silver-Russell syndrome. A total of 30 families were contacted of whom 25 agreed to take part. Eighteen were recruited from the former source and seven from the latter. Those who did not agree did not differ from the remainder in terms of demographic indices, on the basis of available information. The inclusion criteria for the recruitment of subjects were as follows. Firstly, the diagnosis of Silver-Russell syndrome was made when three out of the following five diagnostic features were present: (i) low birth weight (at least 2 SDs below the population mean, adjusting for maternal stature, gestation, ordinal position of the child (first or other born), and gender according to the method of Tanner and Thomson ${ }^{8}$ ); (ii) short stature at the time of the original diagnosis (height for age at least 2 SDs below the population mean ${ }^{9}$ ); (iii) a characteristic craniofacial appearance as described by Russell ${ }^{2}$; (iv) limb or body or facial asymmetry; and (v) clinodactyly. Secondly, the age range was restricted to those between their sixth and 12th birthdays, in order to achieve sufficient homogeneity to allow the assessment of all subjects with the same instruments.

\section{CLINICAL AND GROWTH DATA}

Relevant clinical information about the children was obtained from their hospital case notes and, where appropriate, supplemented by parental accounts. This included: (i) diagnostic features, which were additionally ascertained by clinical examination of the children; (ii) weight and height at the time of diagnosis; (iii) the presence of other clinical features, including a history of major feeding problems in infancy and early childhood, hypoglycaemic episodes, and excessive sweatiness; and (iv) coexisting significant medical illnesses. In addition, the children's general practitioners were approached to provide information on the pregnancy, birth, and the children's anthropometric data at birth (weight, length, and head circumference).

The children's current weight and height were measured at the time of assessment using, respectively, a SECA electronic weighing scale (model 770; Vogel and Halke $\mathrm{GmbH}$ ) and a Raven Magnimetre stadiometer (Raven Equipment; Castlemead Publications). Their occipitofrontal head circumference was measured using a tape made of non-stretchable material according to the method described by Cameron. ${ }^{10}$

Because anthropometric measurements were obtained at different ages for each child, the data have been standardised for age and gender, and are expressed in SD scores. Computation of the SD scores was undertaken by the Centers for Disease Control anthropometric analysis system. ${ }^{11}$ Weight for height ratios were similarly calculated. Occipitofrontal circumferences were also standardised for age and gender ${ }^{12}$ and are expressed as SD scores.
MEASUREMENT OF COGNITIVE ABILITIES

The following instruments were administered: (1) the Wechsler intelligence scale for children (WISC), 3rd edition UK. ${ }^{13}$ Eight out of 13 possible subtests were administered. Pilot studies had shown that child cooperation for the full assessment was compromised by the full version. The choice of subtests was determined by the factorial structure of the instrument ( $p$ 79) and the guidelines for prorating scores ( $p$ 54). ${ }^{13}$ (2) The Neale analysis of reading ability, revised British edition. ${ }^{14}$ The child is asked to read short stories of increasing difficulty until 16 or more errors are made in passages $1-5$, or 20 errors in passage 6 . A set of comprehension questions is provided after each passage to assess the child's understanding of the story. Separate reading ages can be computed for rate, accuracy, and comprehension. (3) The matching familiar figures test (MFF20). ${ }^{15}$ This aims to assess an aspect of cognitive processing which is believed to be closely linked to the child's ability to attend to task, on a dimension ranging from reflectivity to impulsivity. It involves asking the child to match a sample picture, choosing from six simultaneously presented options. The time between the presentation of the pictures and the child's first response is recorded (the 'reaction' time). If the child fails to supply the correct response the first time, $\mathrm{s} / \mathrm{he}$ is asked to continue until the correct answer is given. The total number of erroneous responses is also recorded.

\section{STATISTICAL ANALYSIS}

Most measurements were made on ordinal or interval scales. Summary statistics are presented, where appropriate, as mean values and $1 \mathrm{SD}$. Comparison of means and correlations employed standard parametric methods of analysis where scale properties permitted. Where the data for the sample were compared with a hypothetical population mean (for example, for IQ) a one sample $t$ test was used with $n-1$ degrees of freedom.

\section{Results}

\section{DEMOGRAPHIC FACTORS}

The sample consisted of 20 boys and five girls. Their mean (SD) age was $8.75(1 \cdot 7)$ years. All were white except one (case 11) who was of West Indian parentage. Twenty two $(88 \%)$ of the children were living with both biological parents. The remaining three were living with, respectively, a widowed mother (case 5), adoptive parents (case 11), mother and stepfather (case 14). Assessment of social class, based on father's occupation ${ }^{16}$ gave the following distribution: eight $(32 \%)$ were in managerial or professional occupations, three $(12 \%)$ in assistant professional/clerical occupations, nine $(36 \%)$ in craft/personal/sales related occupations, two $(8 \%)$ worked as plant operatives, and two $(8 \%)$ were unemployed. Eighteen $(72 \%)$ of the families had purchased their own properties, seven $(28 \%)$ were in rented municipal housing. 
Table 1 Anthropometric measurements

\begin{tabular}{|c|c|c|c|c|c|c|c|c|c|c|c|c|c|c|}
\hline \multirow[b]{2}{*}{$\begin{array}{l}\text { Case } \\
\text { No }\end{array}$} & \multirow[b]{2}{*}{ Sex } & \multicolumn{3}{|l|}{ At birth } & \multicolumn{4}{|c|}{ At diagnosis } & \multirow{2}{*}{$\begin{array}{l}\text { Growth } \\
\text { hormone } \\
\text { treatment }\end{array}$} & \multicolumn{5}{|l|}{ Current } \\
\hline & & $\begin{array}{l}\text { Weight } \\
\text { (SD) }\end{array}$ & $\begin{array}{l}\text { Length } \\
(S D)\end{array}$ & $\begin{array}{l}O F C^{\star} \\
(S D)\end{array}$ & $\begin{array}{l}\text { Age } \\
\text { (years) }\end{array}$ & $\begin{array}{l}\text { Weight } \\
\text { (SD) }\end{array}$ & $\begin{array}{l}\text { Height } \\
\text { (SD) }\end{array}$ & $\begin{array}{l}W t h t \dagger \\
(S D)\end{array}$ & & $\begin{array}{l}\text { Age } \\
\text { (years) }\end{array}$ & $\begin{array}{l}\text { Weight } \\
\text { (SD) }\end{array}$ & $\begin{array}{l}\text { Height } \\
\text { (SD) }\end{array}$ & $\begin{array}{l}\text { Wththt } \\
(S D)\end{array}$ & $\begin{array}{l}O F C^{\star} \\
(S D)\end{array}$ \\
\hline $\begin{array}{r}1 \\
2 \\
3 \\
4 \\
5 \\
6 \\
7 \\
8 \\
9 \\
9 \\
10 \\
11 \\
12 \\
13 \\
14 \\
15 \\
16 \\
17 \\
18 \\
19 \\
20 \\
21 \\
22 \\
23 \\
24 \\
25\end{array}$ & $\begin{array}{l}M \\
M \\
M \\
M \\
M \\
M \\
M \\
M \\
\text { F } \\
M \\
M \\
\text { F } \\
M \\
M \\
M \\
\text { F } \\
M \\
M \\
M \\
F \\
M \\
M \\
\text { F } \\
M \\
M\end{array}$ & $\begin{array}{l}-0 \cdot 63 \\
-3 \cdot 28 \\
-3 \cdot 25 \\
-2 \cdot 84 \\
-3 \cdot 66 \\
-2 \cdot 80 \\
-3 \cdot 03 \\
-3 \cdot 22 \\
-3 \cdot 15 \\
-1 \cdot 77 \\
-2 \cdot 19 \\
-4 \cdot 10 \\
-1 \cdot 58 \\
-3 \cdot 03 \\
-0 \cdot 88 \\
-3.94 \\
-3 \cdot 88 \\
-3 \cdot 47 \\
-2 \cdot 40 \\
-3 \cdot 08 \\
-1 \cdot 33 \\
-1 \cdot 85 \\
-1.64 \\
-2.94 \\
-2 \cdot 32\end{array}$ & $\begin{array}{l}-1 \cdot 43 \\
-0 \cdot 19 \\
\text { N/A } \\
\text { N/A } \\
-4 \cdot 89 \\
-9 \cdot 78 \\
-3.95 \\
\text { N/A } \\
\text { N/A } \\
-1 \cdot 41 \\
-3.95 \\
-9 \cdot 17 \\
\text { N/A } \\
-3 \cdot 01 \\
-0.63 \\
\text { N/A } \\
\text { N/A } \\
-4 \cdot 11 \\
0.85 \\
-1.65 \\
-0.63 \\
-2.70 \\
\text { N/A } \\
-3.86 \\
\text { N/A }\end{array}$ & $\begin{array}{l}\text { N/A } \\
-1.00 \\
\text { N/A } \\
1 \cdot 25 \\
\text { N/A } \\
\text { N/A } \\
-1.88 \\
\text { N/A } \\
\text { N/A } \\
-0.85 \\
-0.34 \\
-3.85 \\
\text { N/A } \\
-2.73 \\
\text { N/A } \\
\text { N/A } \\
-4 \cdot 27 \\
\text { N/A } \\
-0.85 \\
-2.56 \\
1.20 \\
0.00 \\
\text { N/A } \\
-0.85 \\
\text { N/A }\end{array}$ & $\begin{array}{l}2.5 \\
3.5 \\
2.8 \\
2.9 \\
2.5 \\
4.0 \\
2.0 \\
9.2 \\
. .2 \\
7.6 \\
4.5 \\
0.7 \\
1.6 \\
1.9 \\
4.0 \\
2.7 \\
6.4 \\
3.0 \\
3.5 \\
5.2 \\
4.5 \\
0.8 \\
8.5 \\
1.3 \\
5.7\end{array}$ & $\begin{array}{l}-2 \cdot 54 \\
-2 \cdot 08 \\
-3 \cdot 22 \\
-3 \cdot 72 \\
-4 \cdot 45 \\
\mathrm{~N} / \mathrm{A} \\
-3 \cdot 30 \\
-2 \cdot 29 \\
-4 \cdot 25 \\
-3 \cdot 18 \\
-2 \cdot 08 \\
-4 \cdot 96 \\
-3 \cdot 63 \\
-3 \cdot 75 \\
-3 \cdot 68 \\
-4 \cdot 13 \\
-3 \cdot 21 \\
\mathrm{~N} / \mathrm{A} \\
-2 \cdot 19 \\
-3 \cdot 43 \\
-2 \cdot 13 \\
-2 \cdot 86 \\
-2 \cdot 28 \\
-4 \cdot 15 \\
-3 \cdot 28\end{array}$ & $\begin{array}{l}-2.91 \\
-1 \cdot 90 \\
-2 \cdot 45 \\
-3 \cdot 38 \\
-9.59 \\
\mathrm{~N} / \mathrm{A} \\
-2 \cdot 75 \\
-2 \cdot 42 \\
-4 \cdot 76 \\
-4 \cdot 08 \\
-2 \cdot 04 \\
-5 \cdot 31 \\
-2 \cdot 99 \\
-3 \cdot 04 \\
-3.93 \\
-2.98 \\
-3 \cdot 13 \\
-3.46 \\
-2 \cdot 71 \\
-3.21 \\
-2 \cdot 83 \\
-2.91 \\
-2 \cdot 41 \\
-4.54 \\
-3.68\end{array}$ & $\begin{array}{l}-1 \cdot 02 \\
-1.34 \\
-2 \cdot 44 \\
-2 \cdot 59 \\
\mathrm{~N} / \mathrm{A} \\
\mathrm{N} / \mathrm{A} \\
-2 \cdot 83 \\
-1 \cdot 23 \\
-2 \cdot 28 \\
-1 \cdot 11 \\
-1 \cdot 21 \\
-1.44 \\
-2.94 \\
-3.30 \\
-2 \cdot 44 \\
-3.09 \\
-1.97 \\
\mathrm{~N} / \mathrm{A} \\
-0.89 \\
-2 \cdot 37 \\
-0.66 \\
-0.67 \\
-1 \cdot 11 \\
-1.67 \\
-1.72\end{array}$ & $\begin{array}{l}- \\
+ \\
+ \\
+ \\
+ \\
+ \\
+ \\
- \\
+ \\
+ \\
+ \\
- \\
+ \\
+ \\
+ \\
+ \\
+ \\
+ \\
+ \\
+ \\
+ \\
- \\
- \\
- \\
+\end{array}$ & $\begin{array}{r}7 \cdot 8 \\
10 \cdot 2 \\
9.0 \\
7.3 \\
8 \cdot 4 \\
7.5 \\
7 \cdot 6 \\
9 \cdot 8 \\
11 \cdot 8 \\
9.7 \\
6 \cdot 6 \\
7 \cdot 6 \\
8 \cdot 8 \\
9 \cdot 0 \\
10 \cdot 0 \\
6 \cdot 0 \\
9 \cdot 0 \\
9 \cdot 1 \\
11 \cdot 6 \\
10 \cdot 3 \\
6.3 \\
6 \cdot 6 \\
9 \cdot 6 \\
7.5 \\
11.8\end{array}$ & $\begin{array}{l}-2 \cdot 06 \\
-1 \cdot 2 \\
-1 \cdot 57 \\
-2 \cdot 32 \\
-4 \cdot 29 \\
-2 \cdot 23 \\
-1 \cdot 44 \\
-2 \cdot 12 \\
-1 \cdot 79 \\
-2 \cdot 09 \\
-2 \cdot 62 \\
-4 \cdot 13 \\
-2 \cdot 36 \\
-2 \cdot 94 \\
-1.32 \\
-2 \cdot 75 \\
-1 \cdot 50 \\
0.07 \\
-1 \cdot 15 \\
-1.99 \\
-1.85 \\
-2 \cdot 90 \\
-2 \cdot 24 \\
-2.97 \\
-0.84\end{array}$ & $\begin{array}{l}-2 \cdot 71 \\
-0.62 \\
-1.05 \\
-1.83 \\
-7.32 \\
-1.95 \\
-0.52 \\
-2 \cdot 41 \\
-1.44 \\
-2 \cdot 76 \\
-2.30 \\
-4.42 \\
-2.65 \\
-2 \cdot 41 \\
-0.76 \\
-2 \cdot 31 \\
-0.89 \\
-0.06 \\
-1.25 \\
-2 \cdot 32 \\
-3.04 \\
-3.27 \\
-2.33 \\
-3.00 \\
-1.00\end{array}$ & $\begin{array}{l}-0.34 \\
-1.22 \\
-1.31 \\
-1.63 \\
-0.92 \\
-1.39 \\
-1.57 \\
-0.90 \\
\text { N/A } \\
-0.40 \\
-1.69 \\
-3.36 \\
-1.05 \\
-2.58 \\
-1.26 \\
-2.05 \\
-0.67 \\
-1.39 \\
\text { N/A } \\
\text { N/A } \\
0.21 \\
-1.54 \\
-1.29 \\
-1.68 \\
\text { N/A }\end{array}$ & $\begin{array}{c}0.20 \\
-1.3 \\
\text { N/A } \\
1.00 \\
\text { N/A } \\
-2 \cdot 20 \\
0.10 \\
-2 \cdot 90 \\
-2.54 \\
-0.3 \\
\text { N/A } \\
-5.70 \\
-0.35 \\
-2 \cdot 10 \\
-1.80 \\
-1.35 \\
-3.95 \\
-3.00 \\
0.80 \\
-2 \cdot 15 \\
0.25 \\
-1.60 \\
0.90 \\
-0.60 \\
0.63\end{array}$ \\
\hline
\end{tabular}

${ }^{\star} \mathrm{OFC}=$ occipitofrontal circumference; $\mathrm{tw} / \mathrm{ht}=$ weight for height ratio. $\mathrm{N} / \mathrm{A}=$ data not available.

CLINICAL DATA

The clinical features of the sample are presented in tables 1 and 2. The mean (SD) age at diagnosis was $3.72(2.32)$ years. Fifteen children $(60 \%)$ were subsequently started on growth hormone treatment. Their mean duration of treatment at the time of the assessment of their cognitive abilities was $3.6(1.7)$ years.

\section{AUXOLOGY}

The mean (SD) birth weight of the sample was $2000(610) \mathrm{g}$ and the mean standardised ${ }^{8}$ birth weight score was $-2.65(0.95)$ SD scores. Eighteen $(72 \%)$ of the children had a birth weight more than -2 SD scores. Five $(20 \%)$ were between -1 and -2 SD scores, and the remaining two $(8 \%)$ were between 0 and -1 SD scores. Seventeen $(68 \%)$ were born between 38 and 42 weeks' gestation, five $(20 \%)$ between 36 and 38 weeks, and three
$(12 \%)$ at below 36 weeks. Three $(12 \%)$ of the children were one of twins (cases 9, 17, 18). The pregnancy and neonatal period were uncomplicated in 21 of the cases. The remaining four had either mild asphyxia (case 19), hypothermia (cases 12 and 16), or neonatal sepsis (case 9).

The mean (SD) standardised height of the sample at the time of their initial diagnosis $(n=24)$ was $-3.45(1.53)$ SD scores, of whom $23(92 \%)$ were more than 2 SD scores below the 50th centile; the mean age of the children at this time was $3.74(2.3)$ years. The mean (SD) standardised weight at diagnosis $(n=23)$ was $-3.24(0.83) \mathrm{SD}$ scores and the corresponding figure for weight for height was -1.83 $(1 \cdot 2)$ SD scores. At the time of their cognitive testing the mean (SD) age of the sample was $8.8(1.8)$ years, their mean height was $-2 \cdot 19$ $(1 \cdot 48)$ SD scores, their mean weight was $-2 \cdot 1$ $(0.95)$ SD scores, and their mean weight for height $(n=21)$ was $-1.33(0.77)$ SD scores.

Table 2 Clinical features and IQ scores

\begin{tabular}{|c|c|c|c|c|c|c|c|c|}
\hline $\begin{array}{l}\text { Case } \\
\text { No }\end{array}$ & $\begin{array}{l}\text { Craniofacial } \\
\text { features }\end{array}$ & Asymmetry & Clinodactyly & $\begin{array}{l}\text { Feeding } \\
\text { problems }\end{array}$ & $\begin{array}{l}\text { Hypoglycaemia } \\
\text { episodes }\end{array}$ & $\begin{array}{l}\text { Full scale } \\
I Q\end{array}$ & $\begin{array}{l}\text { Verbal } \\
I Q\end{array}$ & $\begin{array}{l}\text { Performance } \\
I Q\end{array}$ \\
\hline 1 & + & + & - & + & $\mathbf{N} / \mathbf{K}$ & 102 & 91 & 115 \\
\hline 2 & + & + & + & + & - & 105 & 111 & 96 \\
\hline 3 & + & + & + & + & - & 96 & 95 & 99 \\
\hline 4 & + & + & + & - & + & 126 & 119 & 127 \\
\hline 5 & + & + & + & + & $\mathrm{N} / \mathrm{K}$ & 68 & 92 & 50 \\
\hline 6 & + & - & + & + & - & 94 & 92 & 96 \\
\hline 7 & + & + & + & + & + & 107 & 111 & 101 \\
\hline 8 & + & - & + & - & - & 57 & 65 & 55 \\
\hline 9 & + & + & + & + & - & 85 & 83 & 91 \\
\hline 10 & + & - & + & + & - & 62 & 58 & 71 \\
\hline 11 & - & + & + & + & + & 103 & 100 & 107 \\
\hline 12 & + & - & - & + & - & 61 & 59 & 69 \\
\hline 13 & + & - & + & + & - & 58 & 66 & 55 \\
\hline 14 & + & - & + & - & + & 72 & 74 & 76 \\
\hline 15 & + & + & + & + & - & 71 & 81 & 68 \\
\hline 16 & + & + & + & + & + & 81 & 89 & 77 \\
\hline 17 & + & + & + & + & $\mathbf{N} / \mathbf{K}$ & 81 & 107 & 60 \\
\hline 18 & + & + & + & + & - & 63 & 63 & 68 \\
\hline 19 & + & + & + & + & + & 126 & 122 & 123 \\
\hline 20 & - & + & + & + & - & 46 & 52 & 47 \\
\hline 21 & + & + & + & + & + & 77 & 87 & 71 \\
\hline 22 & + & + & + & + & + & 68 & 70 & 71 \\
\hline 23 & + & + & + & + & - & 106 & 100 & 113 \\
\hline 24 & + & + & + & - & + & 130 & 141 & 104 \\
\hline 25 & + & + & + & - & - & 102 & 104 & 97 \\
\hline
\end{tabular}


All the fathers and $22(88 \%)$ of the mothers were of average height (between the 3rd and 97th centile). ${ }^{9}$ The remaining three mothers were either at or below the 3rd population centile. There was a considerable range in the children's head circumferences, which were on average in the lower range of population norms; mean (SD) $-1.27(1.73)$ SD scores.

\section{CHARACTERISTIC FEATURES}

Twenty three $(92 \%)$ of the children had the distinctive facies, with a small triangularly shaped face, relatively large forehead, a small chin, downturned corners of the mouth, and low set ears. Body asymmetry was present in $19(76 \%)$ and incurving of the fifth finger was found in $23(92 \%)$ of the sample.

\section{HISTORY OF MAJOR FEEDING PROBLEMS AND HYPOGLYCAEMIC EPISODES}

Major feeding problems leading to poor weight gain in infancy and early childhood were reported in $20(80 \%)$ of the cases. Physical causes for the feeding problems were not found in any of the cases. Hypoglycaemic episodes after a short period of fasting were documented in four $(16 \%)$ of the children. In another five $(20 \%)$, episodes resembling hypoglycaemia that manifested as drowsiness, lethargy, excessive sweatiness, or irritability, which were reversed by giving them food, were reported by the parents, but had not been medically investigated. Such episodes were thought to be more common during early childhood, but all were reported to have persisted until the present investigation.

\section{CONCURRENT MEDICAL DIAGNOSIS}

The results of investigations of growth hormone status was available for 18 of the children, four of whom were found to have concomitant growth hormone deficiency. Of these four children, one also had cutaneous neurofibromatosis (case 13), one had congenital heart disease and one had an $\alpha_{1}$-antitrypsin deficiency (case 17). The children who were subsequently treated with growth hormone $(n=15)$ and those who were not $(n=10)$ were similar in age when their diagnosis was made, and had similar standardised

Table 3 Results of WISC intelligence test

\begin{tabular}{|c|c|c|c|c|c|}
\hline \multirow[b]{2}{*}{ Test } & \multicolumn{2}{|c|}{ Silver-Russell syndrome } & \multirow[b]{2}{*}{$\begin{array}{l}\text { Mean (SD) } \\
\text { population }\end{array}$} & \multirow[b]{2}{*}{$\mathrm{t}$} & \multirow[b]{2}{*}{ p Value } \\
\hline & Mean $(S D)$ & $\begin{array}{l}95 \% \text { Confidence } \\
\text { intervals }\end{array}$ & & & \\
\hline $\begin{array}{l}\text { Full scale IQ } \\
\text { Verbal IQ } \\
\text { Performance IQ } \\
\text { Verbal subtests }\end{array}$ & $\begin{array}{l}85.9(23 \cdot 7) \\
89 \cdot 3(22 \cdot 6) \\
84 \cdot 3(23 \cdot 5)\end{array}$ & $\begin{array}{l}76 \cdot 6 \text { to } 95 \cdot 2 \\
80 \cdot 4 \text { to } 98 \cdot 2 \\
75 \cdot 1 \text { to } 93 \cdot 5\end{array}$ & $\begin{array}{l}100(15) \\
100(15) \\
100(15)\end{array}$ & $\begin{array}{l}3 \cdot 0 \\
2 \cdot 4 \\
3 \cdot 3\end{array}$ & $\begin{array}{l}<0.01 \\
<0.05 \\
<0.01\end{array}$ \\
\hline $\begin{array}{l}\text { Comprehension } \\
\text { Information } \\
\text { Similarities } \\
\text { Vocabulary } \\
\text { Performance subtests }\end{array}$ & $\begin{array}{l}8 \cdot 7(4 \cdot 1) \\
8 \cdot 5(4 \cdot 0) \\
7 \cdot 6(4 \cdot 5) \\
7 \cdot 8(4 \cdot 1)\end{array}$ & $\begin{array}{l}7 \cdot 1 \text { to } 10 \cdot 3 \\
6 \cdot 9 \text { to } 10 \cdot 1 \\
5 \cdot 8 \text { to } 9 \cdot 4 \\
6 \cdot 2 \text { to } 9 \cdot 4\end{array}$ & $\begin{array}{l}10(3) \\
10(3) \\
10(3) \\
10(3)\end{array}$ & $\begin{array}{l}1 \cdot 6 \\
1 \cdot 8 \\
2 \cdot 7 \\
2 \cdot 7\end{array}$ & $\begin{array}{l}\text { NS } \\
\text { NS } \\
<0.01 \\
<0.01\end{array}$ \\
\hline $\begin{array}{l}\text { Block design } \\
\text { Object assembly } \\
\text { Picture arrangement } \\
\text { Picture completion } \\
\text { Other subtests }\end{array}$ & $\begin{array}{l}8 \cdot 2(5 \cdot 0) \\
6 \cdot 9(3 \cdot 8) \\
7 \cdot 6(4 \cdot 0) \\
7 \cdot 2(3 \cdot 6)\end{array}$ & $\begin{array}{l}6 \cdot 1 \text { to } 10 \cdot 1 \\
5 \cdot 4 \text { to } 8 \cdot 4 \\
6 \cdot 0 \text { to } 9 \cdot 2 \\
5 \cdot 8 \text { to } 8 \cdot 7\end{array}$ & $\begin{array}{l}10(3) \\
10(3) \\
10(3) \\
10(3)\end{array}$ & $\begin{array}{l}1 \cdot 8 \\
4 \cdot 0 \\
2 \cdot 9 \\
3 \cdot 8\end{array}$ & $\begin{array}{l}\text { NS } \\
<0.001 \\
<0.01 \\
<0.001\end{array}$ \\
\hline Arithmetic & $7 \cdot 7(3 \cdot 9)$ & $6 \cdot 1$ to $9 \cdot 3$ & $10(3)$ & $2 \cdot 9$ & $<0.01$ \\
\hline
\end{tabular}

weight, height, and weight for height SD scores at that time. When seen in the course of this investigation those who were receiving growth hormone were significantly older (mean (SD) $9.47(1.5)$ years) than the remainder (mean $7 \cdot 67(1 \cdot 4)$ years; $t=3 \cdot 1, \mathrm{df} 23, \mathrm{p}=0 \cdot 006)$. They were not, however, significantly taller: mean (SD) $-1.84(1.8)$ and $-2.82(0.7)$ SD scores respectively, and their weights for height were similar: treated group mean $-1.16(0.4)$ and untreated group $-1.52(1 \cdot 0)$.

\section{INTELLECTUAL ABILITY}

A wide range of abilities was found (table 3 ). The mean (SD) full scale IQ (85.9 (23.7)) of the sample was, however, nearly 1 SD below that of the general population (mean 100 (15)). Nine (36\%) of the children scored within the average range of abilities (full scale IQ $85-115)$ and three (12\%) had above average abilities (IQ 116-130). In contrast, five $(20 \%)$ had scores in the borderline range of mental retardation (IQ 70-84) and eight $(32 \%)$ were in the range associated with mild/moderate learning disability (IQ <70). The three children with the highest scores were distinguished by having normal head circumferences at birth (mean $-0.15 \mathrm{SD}$ scores) and at follow up (mean $0.4 \mathrm{SD}$ scores). The scores of the group as a whole on all eight verbal and non-verbal performance subtests of the WISC were for the most part significantly below the population mean (table 3 ). The children did relatively better on verbal skills.

The small number of girls in the sample limited the confidence of findings comparing the performance of boys and girls on cognitive testing. However, girls $(n=5)$ did have lower full scale IQs (mean (SD) $68 \cdot 2(15 \cdot 7)$ ) than boys $(n=20)$ (mean $90.3(23.5)$ ). This difference did not quite reach statistical significance $(p=0.06)$, nor did that for the difference in mean (SD) performance IQ (girls 71 (15.9); boys $87 \cdot 6$ (SD 24)). Girls did have significantly lower verbal IQ scores (mean $70.6(15 \cdot 6)$ ) than boys (mean $94.0 \quad(21.8) ; t=2 \cdot 2 ;$ df 23 , $\mathrm{p}=0.03)$. When the various anthropometric measurements were correlated with IQ scores using Pearson's correlation test, current head circumference measured in standardised scores was found to be significantly correlated with full scale IQ $(r=0.6, \mathrm{p}=0.004)$, performance IQ $(r=0.62, \mathrm{p}=0.002)$, and verbal IQ $(r=0.49, \quad \mathrm{p}=0.02)$. Correlations between standardised head circumference at birth, and between growth of head circumference from birth, and the current IQ scores failed to reach statistical significance. In both cases examination of the scatter plot of those variables and IQ suggested there probably was a relationship, but there were insufficient data $(52 \%$ of sample) to be confident about it.

\section{READING AND ARITHMETIC}

On average the children's reading competence was well below their chronological age (table 4). Their mean (SD) reading comprehension was $15.4(23.8)$ months delayed, their 
Table 4 Arithmetic and reading assessments, with indication of significant degrees of reading retardation

\begin{tabular}{|c|c|c|c|c|c|}
\hline $\begin{array}{l}\text { Case } \\
\text { No }\end{array}$ & $\begin{array}{l}\text { Age } \\
\text { (months) }\end{array}$ & $\begin{array}{l}\text { Arithmetic } \\
\text { scaled score } \\
\text { (maximum 19) }\end{array}$ & $\begin{array}{l}\text { Reading } \\
\text { accuracy age } \\
\text { (months) }\end{array}$ & $\begin{array}{l}\text { Reading } \\
\text { comprehension } \\
\text { age (months) }\end{array}$ & $\begin{array}{l}\text { Reading } \\
\text { rate age } \\
\text { (months) }\end{array}$ \\
\hline 1 & 94 & 9 & $67^{\star}$ & $63^{\star}$ & $63^{\star}$ \\
\hline 2 & 122 & 14 & 157 & 136 & 109 \\
\hline 3 & 108 & 9 & 128 & 110 & 90 \\
\hline 4 & 88 & 11 & 94 & 98 & 113 \\
\hline 5 & 101 & 6 & 98 & 95 & 153 \\
\hline 6 & 90 & 13 & 69 & 81 & 74 \\
\hline 7 & 91 & 11 & 93 & 95 & 130 \\
\hline 8 & 118 & 6 & $59^{\star}$ & $61^{\star}$ & $59^{\star}$ \\
\hline 9 & 142 & 6 & $94^{\star}$ & $98^{\star}$ & $107^{\star}$ \\
\hline 10 & 116 & 2 & $75^{\star}$ & $76^{\star}$ & $76^{\star}$ \\
\hline 11 & 80 & 10 & 68 & 66 & 77 \\
\hline 12 & 91 & 5 & $59^{\star}$ & $59^{\star}$ & $59^{\star}$ \\
\hline 13 & 104 & 1 & $70^{\star}$ & $73^{\star}$ & $73^{\star}$ \\
\hline 14 & 108 & 7 & $83^{\star}$ & 86 & $87^{\star}$ \\
\hline 15 & 120 & 9 & $92^{\star}$ & $81^{\star}$ & $87^{\star}$ \\
\hline 16 & 72 & 4 & 59 & 59 & 59 \\
\hline 17 & 108 & 11 & 87 & 98 & 87 \\
\hline 18 & 109 & 1 & 87 & 89 & 107 \\
\hline 19 & 139 & 9 & 152 & 157 & 147 \\
\hline 20 & 124 & 1 & $59^{\star}$ & $59^{\star}$ & $59 \star$ \\
\hline 21 & 76 & 7 & 69 & 76 & 65 \\
\hline 22 & 78 & 6 & 78 & 68 & 81 \\
\hline 23 & 115 & 12 & 106 & 110 & $83^{\star}$ \\
\hline 24 & 90 & 13 & $157^{\star}$ & $126^{\star}$ & $121^{\star}$ \\
\hline 25 & 142 & 10 & $106^{\star}$ & 119 & $113^{\star}$ \\
\hline
\end{tabular}

${ }^{\star}$ Indicates a value $\geqslant 24$ months behind chronological age.

accuracy was lower by a mean of $14 \cdot 4(29 \cdot 1)$ months, and their rate of reading by a mean of 13.8 (28.9) months. We did not have an appropriate regression equation that would allow us to compute values for 'specific reading retardation', allowing for the children's IQs. However, the proportion falling more than 24 months behind their chronological age in respect of reading accuracy or comprehension is shown in table 4 . The wide SDs indicate the fact that a minority were reading competently: $24 \%$ had a higher level of comprehension, $20 \%$ a greater reading accuracy, and $24 \%$ a reading rate above that expected for their chronological age. Arithmetic competence was not so severely affected, with a mean delay in relation to chronological age of 7 (24) months, and $32 \%$ of children performing at or above the expected level. Those children with above average reading and arithmetic abilities across the four areas of attainment also had above average IQs, a mean difference from the remainder of the sample of 21 points higher.

COGNITIVE PROCESSING

When tested with the matching familiar figures task the mean (SD) reaction time scores were $11.0(4.12)$ for boys and $8.69(3.25)$ seconds for girls. Two boys and one girl were excluded from the analysis on account of extreme values. The mean (SD) error score was 24.95 (11.71) for boys and $33.60(16.80)$ for girls. The differences in mean reaction time and error scores between the boys and the girls in our sample were not statistically significant. These results are very similar to those obtained from a sample of 7-8 year old normal controls in a study by Taylor et al (E Taylor, personal communication) where the mean (SD) reaction time for boys $(n=42)$ was $13(8 \cdot 7)$ seconds, and for girls $(n=48)$ was $11.9(9.2)$ seconds. The corresponding mean error scores were 30 (12) and $30 \cdot 1$ (13) respectively.

\section{EDUCATION}

Nine $(36 \%)$ of the children had been formally statemented as having special educational needs: two of them had been transferred to special schools, the other seven were receiving remedial help in mainstream schools. Their main areas of difficulty tended to be in the area of reading and language skills. Another three children were being given remedial help without having been formally statemented. Twelve children $(48 \%)$ had received speech therapy because of articulation or other developmental speech problems.

\section{Discussion}

The results of our study reveal that children with the Silver-Russell syndrome have cognitive abilities that are, on average, 1 SD below the general population mean in terms of both verbal and non-verbal skills. One third of them have scores within the learning disability range. Underachievement in reading and arithmetic was present in the majority of children. It was not possible with such a small sample to undertake analyses that would make allowance for the children's overall IQ but it is notable that those children with above expected performance in relation to their age were also children with significantly higher IQs than the remainder. Nearly half of the group required remedial education, and a similar proportion had received speech therapy. In a test of cognitive processing, these children did not appear to have poorer attention, in terms of impulsivity/reflectiveness, than a normal age equivalent sample drawn from the general population. Although we did not have direct measures of their parents' intellectual functioning, it is notable that the majority of parents were from the upper end of the social class spectrum, and the ascertainment bias of the sample would, if anything, be expected to have identified children with above average abilities.

Knowledge of the cognitive functioning of children with the Silver-Russell syndrome is of both theoretical and clinical significance. Measures of the global intelligence of children with low birth weight are usually reported to be $0 \cdot 5-1$ SD below those of normal controls. ${ }^{17-19}$ Specific cognitive deficits may also be present, including poor perceptual motor skills, ${ }^{20}$ expressive and receptive language problems, ${ }^{21-24}$ and features suggestive of attention deficit disorder (such as distractibility, inattention, and high levels of activity). ${ }^{2526}$ However, most reports do not distinguish between those whose birth weights were consonant for their gestational age and those who were light for dates. ${ }^{27}$ It is thought that when intrauterine growth retardation commences relatively early in pregnancy, resulting in a reduction in both birth weight and length ('symmetrical' intrauterine growth retardation), in utero brain development is more likely to be affected than when the onset is relatively late ('asymmetrical' intrauterine growth retardation). ${ }^{28}$ Lower scores on various measures of mental development have been found in the 
'symmetrical' intrauterine growth retardation group than the 'asymmetrical' group. ${ }^{29-31}$ The intrauterine growth retardation of the SilverRussell syndrome is believed to begin early in pregnancy. 2532 Other factors that have been shown to play a part in modifying the cognitive development of children with low birth weight include the sex of the child and socioeconomic factors, which may overshadow perinatal complications such as asphyxiation, neonatal hypoglycaemia, and prematurity. ${ }^{26} 2833-36$ Boys, and children from lower socioeconomic classes are more at risk. The finding that girls in this sample had poorer cognitive abilities than boys is contrary to expectation.

The short stature of children with the SilverRussell syndrome is unlikely to make any significant independent contribution to the presence of cognitive impairments, if any. ${ }^{37}$ Where short stature syndromes are associated with specific cognitive deficits, as in some cases of hypopituitarism, ${ }^{38}$ or the Turner's syndrome, ${ }^{39} 40$ this is usually due to the underlying pathology rather than the growth disorder itself. On the other hand, studies have found that in general individuals who are relatively small in size for their age may be perceived by others to be younger than they really are. ${ }^{4142}$ Accordingly, children who are short may elicit a pattern of care from adults that hampers their emotional and psychological development, and this may in turn affect other aspects of their functioning. ${ }^{37}$

These findings suggest that the general cognitive abilities of children with the SilverRussell syndrome are at the lower end of the range reported for representative samples of low birthweight children. ${ }^{21} 4344$ However, low birth weight is a heterogenous condition, and their performance may be similar to other children whose intrauterine growth retardation commences early in pregnancy. ${ }^{29-31}$ Other factors known to influence the cognitive development of children with intrauterine growth retardation probably played less significant a part in our study sample. Complications during pregnancy and birth were seldom reported and most came from relatively advantaged socioeconomic backgrounds. However, many of the children had persistent hypoglycaemia, and this may well have been an aetiological factor for impaired neuronal development. Given their social backgrounds the children's relatively poor performance was, therefore, all the more significant; it would have been interesting to compare it with that of their siblings but we were unable to undertake those assessments. There was no indication that parents who agreed to take part in the study, or the paediatricians whose cases were recruited, agreed to cooperate with the research because of concern about the children's psychosocial or intellectual development.

The finding of a correlation between the children's IQ scores and current (as well as possibly birth) occipitofrontal circumference echoes similar observations from other studies of children with intrauterine growth retardation. 343545 Children with a small head circumference at birth due to intrauterine growth retardation tend to continue to have smaller than average heads in later childhood and adolescence. ${ }^{18} 313435$ Any catch-up head growth that occurs should have done so within the first postnatal year or two, ${ }^{3146}$ so measuring and monitoring these children's head circumference from birth might allow the early identification of those who are at increased risk of impaired cognitive development. Were that feasible, intellectual assessment and special educational provisions could be arranged without delay.

This study highlights important deficits in the cognitive abilities of children with the Silver-Russell syndrome, whose IQ scores are positively correlated with their growth in head circumference. A substantial proportion require remedial educational provisions.

We would like to thank the families who assisted in this study, and in particular the Child Growth Foundation from whom a proportion were recruited. Dr Les Cox provided advice on anthropometric measurements; Jennifer Smith provided administrative assistance. Kelly Lai was supported by a Commonwealth Universities Medical Fellowship.

1 Silver HK, Kiyasu W, George J, Deamer WC. Syndrome of congenital hemihypertrophy, shortness of stature, and elevated urinary gonadotropins. Pediatrics 1853; 12: elevated

2 Russell A. A syndrome of intra-uterine dwarfism recognizable at birth with cranio-facial dysostosis, disproportionately short arms and other anomalies. Proc $R$ Soc Med 1954; 47: 1040-4.

3 Silver HK. Asymmetry, short stature, and variations in sexual development. Am $\mathcal{F}$ Dis Child 1964; 107: 495-513.

4 Patton MA. Russell-Silver syndrome. $\mathcal{F}$ Med Genet 1988; 25 : 557-60.

5 Tanner JM, Lejarraga $\mathrm{H}$, Cameron $\mathrm{N}$. The natural history of the Silver-Russell syndrome: a longitudinal study of of the Silver-Russell syndrome: a longitudinal

6 Saal HM, Pagon RA, Pepin MG. Reevaluation of RussellSal HM, Pagon RA, Pepin MG. Reevaluation
Silver syndrome. $\mathcal{F}$ Pediatr 1985; 107: 733-7.

7 Davies PSW, Valley R, Preece MA. Adolescent growth and pubertal progression in the Silver-Russell syndrome. Arch Dis Child 1988; 63: 130-5.

8 Tanner JM, Thomson AM. Standards for birthweight at gestation periods from 32 to 42 weeks allowing for maternal height and weight. Arch Dis Child 1970; 45: 566-9.

9 Hamill PVV, Drizd TA, Johnson CL, Reed RB, Roche AF Moore WM. Physical growth: National Centre for Health Statistics percentiles. Am $\mathcal{F}$ Clin Nutr 1979; 32: 607-29.

10 Cameron N. The measurement of human growth. London: Croom Helm, 1984.

11 Jordan $\mathrm{MD}$. The CDC anthropometric software package. Version 3. Atlanta, Georgia: Centers for Disease Control, 1986

12 Tanner J. Head circumference standards; birth-16 years. Ware: Castlemead Publications, 1978.

13 Wechsler D. Wechsler intelligence scale for children. 3rd UK revision. Sidcup: The Psychological Corporation, 1992. 4 Neale MD. The Neale analysis of reading ability. Revised British edition. Windsor: NFER-Nelson, 1989.

15 Cairns E, Cammock T. Development of a more reliable version of the matching familiar figures test. Developmental Psychology 1978; 14: 555-60.

16 Office of Population Censuses and Surveys. Standard occupational classification: volume 1. Structure and definition of major, minor and unit groups. London: HMSO, 1990.

17 Fitzhardinge PM, Steven EM. The small-for-date infant. II. Neurological and intellectual sequelae. Pediatrics 1972; 50: 50-7.

18 Henrichsen L, Skinhoj K, Andersen GE. Delayed growth and reduced intelligence in 9-17 year old intrauterine growth retarded children compared with their monozygous co-twins. Acta Paediatr Scand 1986; 75: 31-5.

19 Aylward GP, Pfeiffer SI, Wright A, Verhulst SJ. Outcome studies of low birth weight infants published in the last decade: a metaanalysis. $f$ Pediatr 1989; 115: 515-20.

20 Marlow N, Roberts BL, Cooke RWI. Motor skills in extremely low birth weight children at the age of 6 years. Arch Dis Child 1989; 64: 839-47.

21 The Scottish Low Birthweight Study Group. The Scottish low birthweight study. II. Language attainment, cognitive status, and behavioural problems. Arch Dis Child 1992; 67: $682-6$.

22 Walther FJ, Ramaeker LHJ. Language development at the age of 3 years of infants malnourished in utero. age of 3 years of infants mart

23 Washington DM, McBurney AK, Grunau RVE. Communication skills. In: Dunn HG, ed. Sequelae of low birth weight: the Vancouver study. Clinics in developmental medicine No 95/96. Oxford: Blackwell Scientific, 1986 168-78. 
24 Vohr BR, Garcia Coll C, Oh W. Language development of low-birthweight infants at two years. Dev Med Child Neurol 1988; 30: 608-15.

25 Walther FJ. Growth and development of term disproportionate small-for-gestational age infants at the age of 7 years. Early Hum Dev 1988; 18: 1-11.

26 Hawdon JM, Hey E, Kolvin I, Fundudis T. Born too small - is outcome still affected? Dev Med Child Neurol 1990; 32: 943-53.

27 Wolke D. Supporting the development of low birthweight infants. F Child Psychol Psychiatry 1991; 32: 723-41.

28 Chiswick ML. Intrauterine growth retardation. BMF 1985 291: 845-8.

29 Parkinson CE, Wallis S, Harvey D. School achievement and behaviour of children who were small-for-dates at birth Dev Med Child Neurol 1981; 23: 41-50.

30 Harvey D, Prince J, Bunton J, Parkinson C, Campbell S. Abilities of children who were small-for-gestational-age babies. Pediatrics 1982; 69: 296-300.

31 Villar J, Smeriglio V, Martorell R, Brown CH, Klein RE. Heterogenous growth and mental development of Heterogenous growth and mental development of intrauterine growth-retarded infants durin

32 Gareis FJ, Smith DW, Summitt RL. The Russell-Silver syndrome without asymmetry. $f$ Pediatr 1971; 79: $775-81$

33 Neligan GA, Kolvin I, Scott D McL, Garside RF. Born to soon or born too small. $A$ follow-up study to seven years of age. London: SIMP with Heinemann Medical; Philadelphia: Lippincott, 1976.

34 Ounsted MK, Moar VA, Scott A. Children of deviant birthweight at the age of seven years: health, handicap, size and developmental status. Early Hum Dev 1984; 9: 323-40.

35 Westwood M, Kramer MS, Munz D, Lovett JM, Watters GV. Growth and development of full-term nonasphyxiGV. Growth and development of full-term nonasphyxithrough adolescence. Pediatrics 1983; 71: 376-82.
36 Aylward GP, Verhulst SJ, Bell S. Birth weight, gestational age, and specific dysfunction at 36 months. Dev Med Child Neurol 1988; 30 (suppl 57): 10-1.

37 Skuse D. The psychological consequences of being small. 7 Child Psychol Psychiatry 1987; 28: 641-50.

38 Siegel PT, Hopwood NJ. The relationship of academic achievement and the intellectual functioning and affective conditions of hypopituitary children. In Stabler B, hypopituitary children. In: Stabler B Underwood LE, eds. Slow grows the child. London Erlbaum, 1986: 57-71.

39 Rovet J, Netley C. Processing deficits in Turner's syndrome Developmental Psychology 1982; 18: 77-94.

$40 \mathrm{McCauley}$ E, Kay T, Ito J, Treder R. The Turner McCauley E, Kay T, Ito J, Treder R. The Turner behaviour problems. Child Dev 1987; 58: 464-73.

41 Alley TR. Growth-produced changes in body shape and size as determinants of perceived age and adult caregiving. Child Dev 1983; 54: 241-8.

42 Rotnem DL. Size versus age: ambiguities in parenting short-statured children. In: Stabler B, Underwood LE, eds. Slow grows the child. London: Erlbaum, 1986: 178-90.

43 Francis-Williams J, Davies PA. Very low birthweight and later intelligence. Dev Med Child Neurol 1974; 16: 709-28.

44 Saigal S, Szatmari P, Rosenbaum P, Campbell D, King S Intellectual and functional status at school entry of children who weighed $1000 \mathrm{~g}$ or less at birth: a regiona perspective of births in the 1980s. F Pediatr 1990; 116 409-16.

45 Dunn HG, Hughes CJ, Schulzer M. Physical growth. In: Dunn HG, ed. Sequelae of low birth weight: the Vancouver study. Clinics in developmental medicine No $95 / 96$. Oxford: Blackwell Scientific, 1986: 33-53.

46 Brandt I. Growth dynamics of low birth weight infants with emphasis on the perinatal period. In: Falkner F, Tanner JM, eds. Human growth Volume 2: postnatal growth. New York: Plenum Press, 1978: 557-617. 